of dehydrated pelleted hay transit through the digestive tract. Nevertheless, this increase in calcium urinary and faecal excretion may be responsible for the bone deformation observed in lambs fed dehydrated pelleted hay during a long time.

In lambs fed dehydrated pelleted rye-grass hay, the daily urinary excretion of inorganic phosphorus was very high (Table III) and reached values similar to those observer in renal-stone prone lambs. Such an increase in daily urinary excretion of inorganic phosphorus was not observed in lambs fed dehydrated pelleted lucerne hay. Thus, the calcium content of the hay seems to play a major role in the control of the arinary excretion of inorganic phosphorus in lambs.

\title{
Effect on breeding of cabbage feeding
}

\author{
G. BRICE and C. JARDON \\ I.T.O.V.I.C., 34, bd de la Gare, 35500 Toulouse
}

Cabbage is used more and more at cortain periods of the year as the "sole meal " in ewes kept on zero grazing. However, depending on the variety or growth stage at crop time, this food contains goitrogenic substances which disturb the working of the thyroid and perhaps ovarian glands by stopping iodine assimilation.

When fed to ewes at the end of pregnancy, cabbage causes a high mortality rate of the lambs at birth and disturbs their growth. The month before and after artifical insemination, this green fodder leads to lower fertility and prolificacy rates.

It seems that these difficulties ane fewer when cabbage feeding is restricted. In spite of this, cabbage remains an attractive food in pasture or zero grazing, but should be reserved for lactating or dried-up ewes, and not be given to mating ewes, as long as an efficient correcting factor has not been found.

\section{Home range behaviour and use of pastures by unherded sheep on an alpine range}

\author{
Y. FAVRE and J. P. SIGNORET \\ C.T.G.R.E.F., I.N.E.R.M., Grenoble \\ Laboratoire de Recherches sur le comportement sexucl et social, \\ Centre de Recherches de Tours, I.N.R.A., \\ Nousilly 37380 Monnaie (France)
} studied.

The home range behaviour of sheep kept on an alpine range in high altitudes in the Alps is

Individual flocks remain as a stable social unit without mixing. Each uses an exclusive home range with stable camping sites and grazing areas, although the flocks often group together, especially during the rumination period in the middle of the day. When meeting during grazing, the flocks separate as soon as possible. As a consequence, the pasture is fairly uniformly used, and grass production is correctly utilized by the sheep.

In this very difficult environment, weekly checking by a shepherd is sufficient to limit the losses to $x \mathrm{p}$. roo during each of the 4 years of observation.

Such a system could be profitable for using mountain ranges. 